\title{
Level of Anxiety and Depression and Its Clinical and Sociodemographic Determinants among the Parents of Children with Cancer Undergoing Chemotherapy
}

\author{
Shivayan Srivastava ${ }^{1} \quad$ Vikas Menon $^{2} \quad$ Smita Kayal $^{1}$ \\ ${ }^{1}$ Department of Medical Oncology, Jawaharlal Institute of \\ Postgraduate Medical Education and Research, Puducherry, India \\ 2Department of Psychiatry, Jawaharlal Institute of Postgraduate \\ Medical Education and Research, Puducherry, India
}

\author{
Meenatchi Hari ${ }^{1} \quad$ Biswajit Dubashi ${ }^{1}$
}

\begin{abstract}
Address for correspondence Biswajit Dubashi, DM, Department of Medical Oncology, Jawaharlal Institute of Postgraduate Medical Education and Research, Dhanvantri Nagar, Puducherry 605006, India (e-mail: drbiswajitdm@gmail.com).
\end{abstract}

\begin{abstract}
Keywords

- cancer

- pediatric

- parents

- depression

- anxiety

Objective The aim of this study was to find the level of anxiety and depression and its clinical and sociodemographic determinants among the parents of children with cancer on chemotherapy.

Materials and Methods Hamilton-A (HAM-A) and Hamilton-D (HAM-D) scales were used to assess anxiety and depression, respectively, in this cross-sectional study. The assessed parents were administered the questionnaire along with collection of sociodemographic and clinical data through a structured data collection proforma between August 2018 and November 2018.

Statistical Analysis The sociodemographic factors and the clinical characteristics were analyzed and have been expressed descriptively and associations between the sociodemographic characteristics, clinical characteristics of the children, and the calculated scores obtained from HAM-A and HAM-D scales were analyzed using chi-squared test. A $p$-value of $<0.05$ was considered statistically significant.

Results Out of 101 parents, $86(85.14 \%)$ were found to have a mild, moderate, or severe depression score. Parents of children with solid tumors undergoing chemotherapy had higher frequency of severe and very severe depression. Majority of the parents (56.4\%) assessed with HAM-A scale had mild level of anxiety that was significantly affected by the level of education.

Conclusion This study confirmed a very high frequency of depression and anxiety in the parents of children affected with cancer undergoing chemotherapy. Type of cancer (solid or hematological) was found to be a predictor of depression, while education level was found to be a predictor of anxiety in the parents.
\end{abstract}

\section{Introduction}

About 1.6 to $4.8 \%$ of all the cancers in India are diagnosed in children below 15 years of age with an overall incidence of 38 to 124 per million and the rate is increasing according to population-based cancer registry survey 2009 to $2011 . .^{2}$ Compared with population norms, the parents of children with cancer have reported worse psychosocial and physical quality of life in all psychological domains. ${ }^{3}$ These parents face the psychological effects of cancer indirectly in the form

DOI https://doi.org/ 10.1055/s-0040-1713581 ISSN 0976-3147. of invasive, expensive, and long chemotherapy treatment given to their child that causes a large number of distressing and unavoidable side effects. ${ }^{4}$

Depression is one of the major causes of poor health and disability in the world and caring for a child with cancer has been associated with increased chances of development of depressive symptoms in parents that are clinically relevant., According to a study conducted by Ghufran et al in Aga Khan University among mothers of pediatric cancer patients, $78 \%$ were found to be depressed. ${ }^{7}$ Parents of children who are 
newly diagnosed or on active cancer therapy report higher levels of anxiety than those of children who are off active cancer therapy. ${ }^{8}$ They also report significant deterioration of their own health due to worse diet and nutrition, decreased physical activity, and less time spent doing enjoyable activities. ${ }^{9}$ It has been found that the depression found in the patients is linked to the depression in their caregivers. ${ }^{10}$ Hence, there is a need to assess levels of anxiety and depression in the parents and find its associated factors to help plan appropriate interventions that may mitigate caregiver distress and possibly promote mental health in the children as well.

Parents of children with cancer have also reported levels of anxiety higher than that present in the cancer patients themselves. ${ }^{11}$ All these evidences suggest that cancer is a disease that affects the entire family as opposed to only the child suffering from it.

Few studies have been done to find the association of various sociodemographic and clinical variables with the levels on anxiety and depression of parents with children undergoing chemotherapy, especially in India. No such study has been conducted in the population being studied to the best of our knowledge. Depression is one of the biggest hidden issues plaguing the society due to the stigma that comes associated with it. To bring to light the mental health being faced the parents, this study was conducted.

\section{Materials and Methods}

The cross-sectional study was conducted in the Department of Medical Oncology, Jawaharlal Nehru Institute of Medical Education and Research (JIPMER), Puducherry, at the Regional Cancer Centre (RCC) between August and November 2018. The inclusion criteria of the study included parents (21-50 years old) of children ( 0 -18 years old) who had been receiving chemotherapy as the primary treatment for cancer at the RCC, JIPMER. The parents with prior clinical depression or psychiatric illness, with any significant family death in the past 6 months, and with chronic illnesses and malignancies were excluded from the study.

The study sample consisted of parents directly involved in the care of the child. They were invited to participate in the study when visiting the hospital along with their children for treatment or follow-up. The parents fulfilling the inclusion criteria were informed about the study, written consent was taken, and the validated Hamilton-A (HAM-A) and Hamilton-A (HAM-D) questionnaires in Tamil language (due to preponderance of Tamil-speaking patients at the center) were administered by a clinicosocial worker.

One-hundred eight of the 191 parents eligible for the study participated in it. Out of the 108 samples collected, 7 forms were disregarded from the study due to incomplete data or due to errors in collection of information. A total of 101 samples were considered.

\section{Sociodemographic and Clinical Variables}

Information on the age of the parents, economic status, education, occupation, distance of home from the treatment center, number of children in the family, gender, and age of affected child is collected at the time of administration of the questionnaire through a structured data collection proforma. The clinical details of the case were obtained through the departmental case records.

\section{HAM-A and HAM-D Scales}

To assess the anxiety and depression, HAM-A and HAM-D scales were administered.

HAM-D is a questionnaire consisting of 17 items. It helps to assess depression by rating the severity of depression in terms of insomnia, somatic symptoms, mental retardation, weight loss, agitation, and feeling of guilt. It is designed for adults. There are eight questions that are scored from 0 to 40 being "not present" to 4 being "severe." Nine are scored from 0 to $2 .{ }^{12}$ The scoring is classified into different categories as follows: $0-7=$ normal; $8-13=$ mild depression; $14-18=$ moderate depression; $19-22$ = severe depression; more than $23=$ very severe depression.

HAM-A is used to rate the severity of anxiety in a patient. It consists of 14 items. There are 14 questions containing several symptoms, and each symptom is rated on a scale ranging from 0 to 4 with 0 being "least severe" and 4 being "most severe." All these scores help to calculate an overall score that indicates the severity of a person's anxiety. There's a total score range of 0 to 56 , where $<17$ indicates mild severity, 18 to 24 indicates mild-to-moderate anxiety, and 25 to 30 indicates moderate-to-severe anxiety levels. ${ }^{13}$

\section{Statistical Analysis}

The data collected was analyzed using Stata Version 12. The sociodemographic variables and the clinical characteristics were analyzed and have been expressed descriptively in frequency and percentages. Associations between the sociodemographic characteristics, clinical characteristics of the children, and the calculated anxiety and depression scores obtained from HAM-A and HAM-D scales were analyzed using chi-squared test. A $p$-value of $<0.05$ was considered statistically significant.

\section{Results and Discussion}

A total of 108 people took part in this study. However, due to missing information and incomplete filling of the questionnaire, only 101 responses were considered. Out of the 101 parents, most (78.2\%) were mothers. The median age of the parents participating in the study was 31 with a range of 23 years to 47 years. The distribution of the age is given in - Table 1. Sixty-six $(65.4 \%)$ of the parents were unemployed with all the unemployed mothers being homemakers by profession, while majority of the employed parents were self-employed as daily wage laborers. The median number of people living at homes of the parents was 4 with a range of 2 to 12 . The median age of the children associated with the study was 4 years with a range of 1 to 18 years of age. This information is summarized in - Table 1 .

Out of the 101 parents studied, sixty-two (61.4\%) had some form of suicidal tendencies. Eighty-seven (86.1\%) parents reported insomnia present as difficulty in falling 
Table 1 Sociodemographic characteristics of parents and children

\begin{tabular}{|c|c|c|}
\hline Variables & $n(101)$ & Percentage \\
\hline \multicolumn{3}{|l|}{ Gender of parents } \\
\hline Fathers & 22 & 21.78 \\
\hline Mothers & 79 & 78.22 \\
\hline \multicolumn{3}{|l|}{ Age distribution of parents } \\
\hline $21-30 y$ & 49 & 48.51 \\
\hline $31-40 y$ & 38 & 35.64 \\
\hline$>40 y$ & 14 & 13.86 \\
\hline \multicolumn{3}{|l|}{ Education of parents } \\
\hline No formal education & 16 & 15.84 \\
\hline Primary/Secondary & 51 & 50.50 \\
\hline Intermediate/Higher education & 34 & 33.66 \\
\hline \multicolumn{3}{|l|}{ Occupation of parents } \\
\hline Unemployed & 66 & 65.35 \\
\hline Employed & 35 & 34.65 \\
\hline \multicolumn{3}{|l|}{ Distance of home from cancer center } \\
\hline$<20 \mathrm{~km}$ & 13 & 12.87 \\
\hline $21-100 \mathrm{~km}$ & 41 & 40.59 \\
\hline$>101 \mathrm{~km}$ & 47 & 46.53 \\
\hline \multicolumn{3}{|l|}{ Economic class of family } \\
\hline Lower & 81 & 80.20 \\
\hline Middle & 12 & 11.88 \\
\hline Upper & 8 & 7.92 \\
\hline \multicolumn{3}{|l|}{ Number of children in family } \\
\hline 1 & 23 & 22.77 \\
\hline 2 & 50 & 49.50 \\
\hline$>2$ & 28 & 27.72 \\
\hline \multicolumn{3}{|l|}{ Gender distribution of children } \\
\hline Male & 62 & 62.6 \\
\hline Female & 39 & 39.3 \\
\hline \multicolumn{3}{|l|}{ Age distribution of children } \\
\hline $0-4 y$ & 35 & 34.6 \\
\hline $5-9 y$ & 29 & 28.7 \\
\hline $10-14 y$ & 28 & 27.7 \\
\hline $15-19 y$ & 9 & 8.9 \\
\hline
\end{tabular}

asleep, waking during the night, or waking in early hours of the morning and difficulty in falling asleep again. Thirtythree $(32.7 \%)$ parents reported somatic form of anxiety with gastrointestinal symptoms such as indigestion and cardiovascular symptoms such as palpitations, headaches, and respiratory symptoms.

Out of 101 children, sixty-five (64\%) had been diagnosed with a hematological cancer, while thirty-six (35.6\%) children had been diagnosed with a solid cancer. Most of the parents (46.53\%) studied had children diagnosed more than 6 months ago from the date of assessment. The distribution of time since diagnosis and time since initiation of chemotherapy has been shown in - Table 2 .
Out of 101 parents assessed, eighty-six (85.14\%) parents were found to be depressed. The mean HAM-D score was 14.88 that falls within the range of moderate depression (standard deviation $[S D]=6.63)$. Eighteen $(17.82 \%)$ parents were mildly depressed with a score range of 8 to 13, thirty eight $(37.62 \%)$ parents were moderately depressed with a score range of 14 to 18 , eighteen (17.82\%) parents were severely depressed with a score range of 19 to 22 , and twelve (11.80\%) parents were very severely depressed with a score of more than 23. For calculation of anxiety levels, the mean HAM-A score was 17.64 that falls within the range of moderate anxiety ( $S D=10$ ) with the majority $(56.44 \%)$ of the parents having mild anxiety with a score of $<17,17(16.83 \%)$ 
Table 2 Clinical characteristics of pediatric cancer patients studied

\begin{tabular}{|l|l|l|}
\hline Variables & $\boldsymbol{n}=\mathbf{1 0 1}$ & Percentage \\
\hline Type of cancer & & \\
\hline Solid & 36 & 35.64 \\
\hline Hematological & 65 & 64.36 \\
\hline Time since diagnosis & & \\
\hline$<1$ mo & 19 & 18.81 \\
\hline $1-6$ mo & 33 & 32.67 \\
\hline$>6$ mo & 49 & 48.52 \\
\hline $\begin{array}{l}\text { Number of outpatient/inpatient } \\
\text { visits in previous month }\end{array}$ & & \\
\hline $0-5$ & 54 & 53.47 \\
\hline $6-10$ & 34 & 33.66 \\
\hline$>10$ & 13 & 12.87 \\
\hline $\begin{array}{l}\text { Time since initiation of } \\
\text { chemotherapy }\end{array}$ & & \\
\hline$<1$ mo & 26 & 27.74 \\
\hline $1-6$ mo & 28 & 46.53 \\
\hline$>6$ mo & 47 & \\
\hline
\end{tabular}

Table 3 Incidence and distribution of depression and anxiety by severity

\begin{tabular}{|l|l|l|}
\hline Variables & $\mathbf{n = 1 0 1}$ & Percentage \\
\hline Depression & & \\
\hline Present & 86 & 85.14 \\
\hline Absent & 15 & 14.85 \\
\hline Depression grade & & \\
\hline Absent & 15 & 14.85 \\
\hline Mild/moderate & 56 & 55.45 \\
\hline Severe/very severe & 30 & 29.70 \\
\hline Anxiety grade & & \\
\hline Mild & 57 & 56.44 \\
\hline Moderate & 17 & 16.83 \\
\hline Severe & 27 & 26.73 \\
\hline Anxiety & & \\
\hline Present & 101 & 100 \\
\hline Absent & 0 & 0 \\
\hline
\end{tabular}

of the parents having moderate anxiety with a score range of 18 to 24 , and twenty-seven (26.73\%) of the parents having severe anxiety with a score range of more than or equal to 25 . The above information is summarized in - Table 3.

It was observed that the frequency of severe and very severe depression is seen more in parents of children diagnosed with solid cancer as compared with parents of children diagnosed with hematological cancer $(p=0.04)$. A significant $p$-value of 0.013 was also found in the association between the education of the parents and the level of anxiety seen in them. The frequency of severe anxiety was found to be more in the parents with lesser education as compared with parents with higher level of education (-Tables 4 and 5 ).

\section{Discussion}

Parents of pediatric cancer patients are the main source of emotional support to them. ${ }^{14}$ Hence, it is essential to evaluate and assess their mental health to ensure proper care of the children. This study found the frequency of depression among the biological parents of pediatric cancer patients to be $85.14 \%$ that is significantly higher than prevalence of $15.4 \%$ found in the general population according to the largest population-based study in South India to determine the prevalence of depression done in Chennai among 26,001 subjects. ${ }^{15}$ A study conducted in Iran showed the depression rate in mothers of leukemia-diagnosed children to be $91 \% .{ }^{16}$ Ghufran et al conducted a study that showed the depression rate in mothers of cancer-diagnosed children to be $78 \%$ which is relatively lower than the depression rate found in this study. ${ }^{7}$ The study found that the majority of parents (69\%) had mild level of depression, as opposed to this study in which majority of the parents (37.62\%) had moderate level of depression. About $61.4 \%$ of the parents reported having some form of suicidal thoughts. They were referred to a clinical psychologist in the institute.

About $56.4 \%$ of the parents were found to have mild level of anxiety, $16.8 \%$ were found to have moderate level of anxiety, and $26.7 \%$ were found to have severe level of anxiety. According to a study conducted among male adults in India, the rate of mild anxiety was found to be $24.4 \%$ that is significantly lower than the rate found for the male parents in this study (54.5\%). ${ }^{17}$ There were no significant differences between the levels of anxiety in mothers and fathers. A statistically significant association was found between the level of anxiety and the education level of the parents. The parents with lesser level of education were found to have higher frequency of severe anxiety when compared with parents with higher level of education. This could be possibly due to difficulties in understanding the disease in parents with no formal education. There were no other significant associations found. Prior literature with a significant association between education and anxiety in case of caregivers of cancer afflicted children could not be found. However, a separate study done on caregivers of mentally ill patients noted that caregivers with less education were found to have more anxiety as compared with the caregivers with primary and secondary levels of education. ${ }^{18}$

There are multiple factors responsible for the presence of high rates of depression among parents of pediatric cancer patients. A study conducted in 2015 by Halina Sklenarova found that more distress was present in parents with unmet information and healthcare needs and unmet psychological needs. ${ }^{19}$ Hence, the lack of information, uncertainty, and lack of access to proper psychological counselling might be important factors causing high depression levels in the parents. It is also due to the presence of low social support. Chemotherapy leads to a variety of side effects such as nausea, hair loss, and vomiting that have been described as the 
534 Anxiety and Depression in the Parents of Children Affected with Cancer Undergoing Chemotherapy Srivastava et al.

Table 4 Associations between sociodemographic and clinical factors with level of depression

\begin{tabular}{|c|c|c|c|c|c|c|c|c|c|}
\hline \multirow[t]{2}{*}{ Variable } & \multicolumn{2}{|c|}{ No depression } & \multicolumn{2}{|c|}{$\begin{array}{c}\text { Mild/moderate } \\
\text { depression }\end{array}$} & \multicolumn{2}{|c|}{$\begin{array}{c}\text { Severe/very severe } \\
\text { depression }\end{array}$} & \multicolumn{2}{|c|}{ Total } & \multirow[t]{2}{*}{$p$-Value } \\
\hline & Frequency & $\%$ & Frequency & $\%$ & Frequency & $\%$ & Frequency & $\%$ & \\
\hline Gender of parents & & & & & & & & & \multirow[t]{3}{*}{$p=0.59$} \\
\hline Male & 2 & 13.3 & 12 & 21.5 & 8 & 26.6 & 22 & 21.7 & \\
\hline Female & 13 & 86.7 & 44 & 78.5 & 22 & 73.4 & 79 & 78.3 & \\
\hline \multicolumn{9}{|l|}{ Age of parents } & \multirow[t]{4}{*}{$p=0.84$} \\
\hline $21-30 y$ & 7 & 46.6 & 29 & 51.7 & 13 & 43.3 & 49 & 48.5 & \\
\hline $31-40 y$ & 5 & 33.4 & 21 & 37.5 & 12 & 40.0 & 38 & 37.6 & \\
\hline$>40 y$ & 3 & 20.0 & 6 & 10.8 & 5 & 16.7 & 14 & 13.9 & \\
\hline \multicolumn{9}{|l|}{ Education of parents } & \multirow[t]{4}{*}{$p=0.29$} \\
\hline No education & 1 & 6.7 & 11 & 19.6 & 4 & 13.3 & 16 & 15.8 & \\
\hline Primary/secondary & 10 & 66.7 & 23 & 41.1 & 18 & 60.0 & 51 & 50.5 & \\
\hline Inter/higher & 4 & 26.6 & 22 & 39.3 & 8 & 26.7 & 34 & 33.7 & \\
\hline $\begin{array}{l}\text { Occupation of } \\
\text { parents }\end{array}$ & & & & & & & & & $p=0.37$ \\
\hline Unemployed & 12 & 80.0 & 34 & 60.7 & 20 & 66.7 & 66 & 65.3 & \\
\hline Employed & 3 & 20.0 & 22 & 39.3 & 10 & 33.3 & 35 & 34.7 & \\
\hline \multicolumn{9}{|l|}{ Economic class } & \multirow[t]{6}{*}{$p=0.23$} \\
\hline Lower & 10 & 66.6 & 35 & 62.5 & 17 & 56.7 & 62 & 61.4 & \\
\hline Lower middle & 3 & 20.0 & 6 & 10.7 & 10 & 33.3 & 19 & 18.8 & \\
\hline Middle & 1 & 6.7 & 9 & 16.1 & 2 & 6.7 & 12 & 11.9 & \\
\hline Upper middle & 0 & 0 & 4 & 7.1 & 1 & 3.3 & 5 & 4.9 & \\
\hline Upper & 1 & 6.7 & 2 & 3.6 & 0 & 0 & 3 & 3.0 & \\
\hline $\begin{array}{l}\text { Distance from cancer } \\
\text { center }\end{array}$ & & & & & & & & & $p=0.42$ \\
\hline$<20 \mathrm{~km}$ & 1 & 6.7 & 9 & 16.1 & 3 & 10.0 & 13 & 12.9 & \\
\hline $21-100 \mathrm{~km}$ & 9 & 60.0 & 19 & 33.9 & 13 & 43.3 & 41 & 40.6 & \\
\hline$>100 \mathrm{~km}$ & 5 & 33.3 & 28 & 50.0 & 14 & 46.7 & 47 & 46.5 & \\
\hline \multicolumn{9}{|l|}{ Number of children } & \multirow[t]{4}{*}{$p=0.51$} \\
\hline 1 & 6 & 40.0 & 12 & 21.4 & 5 & 16.7 & 23 & 22.8 & \\
\hline 2 & 6 & 40.0 & 28 & 50.0 & 16 & 53.3 & 50 & 49.5 & \\
\hline$>2$ & 3 & 20.0 & 16 & 28.6 & 9 & 30.0 & 28 & 27.7 & \\
\hline \multicolumn{9}{|l|}{ Age of children } & \multirow[t]{5}{*}{$p=0.23$} \\
\hline $0-4$ & 3 & 20.0 & 24 & 42.8 & 8 & 26.7 & 35 & 34.6 & \\
\hline $5-9$ & 4 & 26.7 & 13 & 23.2 & 12 & 40.0 & 29 & 28.8 & \\
\hline $10-14$ & 7 & 46.7 & 15 & 26.8 & 6 & 20.0 & 28 & 27.7 & \\
\hline 15-19 & 1 & 6.6 & 4 & 7.2 & 4 & 13.3 & 9 & 8.9 & \\
\hline \multicolumn{9}{|l|}{ Children gender } & \multirow[t]{3}{*}{$p=0.90$} \\
\hline Male & 10 & 66.7 & 34 & 60.7 & 18 & 60.0 & 62 & 61.4 & \\
\hline Female & 5 & 33.3 & 22 & 39.3 & 12 & 40.0 & 39 & 38.6 & \\
\hline \multicolumn{9}{|l|}{ Time since diagnosis } & \multirow[t]{6}{*}{$p=0.37$} \\
\hline$<1 \mathrm{mo}$ & 6 & 40.0 & 9 & 16.1 & 4 & 13.3 & 19 & 18.8 & \\
\hline $1-3 \mathrm{mo}$ & 2 & 13.3 & 8 & 14.3 & 5 & 16.7 & 15 & 14.8 & \\
\hline $3-6 \mathrm{mo}$ & 4 & 26.7 & 10 & 17.8 & 4 & 13.3 & 18 & 17.8 & \\
\hline 6-12 mo & 1 & 6.7 & 12 & 21.4 & 8 & 26.7 & 21 & 20.8 & \\
\hline$>12 \mathrm{mo}$ & 2 & 13.3 & 17 & 30.4 & 9 & 30.0 & 28 & 27.8 & \\
\hline
\end{tabular}


Table 4 (Continued)

\begin{tabular}{|c|c|c|c|c|c|c|c|c|c|}
\hline \multirow[t]{2}{*}{ Variable } & \multicolumn{2}{|c|}{ No depression } & \multicolumn{2}{|c|}{$\begin{array}{c}\text { Mild/moderate } \\
\text { depression }\end{array}$} & \multicolumn{2}{|c|}{$\begin{array}{c}\text { Severe/very severe } \\
\text { depression }\end{array}$} & \multicolumn{2}{|c|}{ Total } & \multirow[t]{2}{*}{$p$-Value } \\
\hline & Frequency & $\%$ & Frequency & $\%$ & Frequency & $\%$ & Frequency & $\%$ & \\
\hline \multicolumn{9}{|l|}{ Cancer type } & \multirow[t]{3}{*}{$p=0.04$} \\
\hline Hematological & 12 & 80.0 & 39 & 69.7 & 14 & 46.7 & 65 & 64.4 & \\
\hline Solid & 3 & 20.0 & 17 & 30.3 & 16 & 53.3 & 36 & 35.6 & \\
\hline $\begin{array}{l}\text { Time since initiation } \\
\text { of chemotherapy }\end{array}$ & & & & & & & & & \multirow[t]{6}{*}{$p=0.49$} \\
\hline$<1 \mathrm{mo}$ & 7 & 46.7 & 12 & 21.4 & 7 & 23.3 & 26 & 25.7 & \\
\hline $1-3 \mathrm{mo}$ & 2 & 13.3 & 9 & 16.1 & 3 & 10.0 & 14 & 13.9 & \\
\hline $3-6$ mo & 3 & 20.0 & 8 & 14.3 & 3 & 10.0 & 14 & 13.9 & \\
\hline $6-12 \mathrm{mo}$ & 1 & 6.7 & 12 & 21.4 & 8 & 26.7 & 21 & 21.0 & \\
\hline$>12 \mathrm{mo}$ & 2 & 13.3 & 15 & 26.8 & 9 & 30.0 & 26 & 25.5 & \\
\hline \multicolumn{9}{|l|}{ Number of visits } & \multirow[t]{4}{*}{$p=0.06$} \\
\hline $0-5$ & 5 & 33.3 & 34 & 60.7 & 15 & 50.0 & 54 & 50.5 & \\
\hline $6-10$ & 5 & 33.3 & 16 & 28.6 & 13 & 43.3 & 34 & 33.7 & \\
\hline$>10$ & 5 & 33.3 & 6 & 10.7 & 2 & 6.7 & 13 & 12.8 & \\
\hline
\end{tabular}

side effects causing the most distress. ${ }^{20}$ The presence of such side effects in their children might be a factor adding to the deterioration of mental health.

There were no associations found between the level of depression and the age of the parents, their education level, their employment status, the number of children in the family, and gender of the child in this study that was consistent to the findings of a study done in Iran among mothers of children with leukemia which also found no associations in these factors. ${ }^{16}$ However, there were associations found between the socioeconomic class of the family and the level of depression in that study which were absent in this study. The income data collected in this study was self-declared income by parents, majority of whom are employed as daily wage laborers with high variability in monthly income which could have led to erroneous reporting and could be a reason for the missing association. However, Erkan and Kaplan did not find a statistically meaningful difference when the level of depression was compared with respect to income level. ${ }^{21}$

A significant association was found between the form of cancer and the level of depression in the parents in this study. Parents with children diagnosed with solid cancer were found to have higher level of severe or very severe depression present when compared with parents of children diagnosed with hematological cancer. A similar result was found in a study conducted in Jordan which found that the parental distress was lower in children diagnosed with lymphoma (a hematological tumor) when compared with other diagnosis. ${ }^{22}$ This could be due to the fact the hematological tumors, even in advanced stages, are more curable than solid tumors. Solid tumors in advanced stages are associated with poor prognosis. The worse prognosis of solid tumors is one possible reason for the association found. A 10-year survival rate for patients with Wilms tumor, Ewing sarcoma, neuroblastoma, osteosarcoma, and rhabdomyosarcoma was 76.6, 30.6, 54.4, 29.3, and 27.5\%, respectively, for children diagnosed in the time period of 2000 to 2010, while the 10-year survival rate for ALL, the most common hematological cancer is as high as $85.5 \%$ in the time period of 2000 to $20100^{23,24}$ Another reason for the lower frequency of severe and very severe levels of depression in case of hematological tumors could be intensive initial chemotherapy and intensive counseling immediately following the diagnosis that is not seen in case of solid tumors.

\section{Conclusion}

This study confirmed a very high frequency of depression and anxiety in the parents of children affected with cancer undergoing chemotherapy. Type of cancer (solid or hematological) was found to be a predictor of depression, while education level was found to be a predictor of anxiety in the parents.

\section{Clinical Implications}

It maybe concluded that screening for depression and anxiety followed by early therapeutic interventions by psychologists and psychiatrists in the form of counseling and other clinically relevant methods can help to improve the mental health of the parents and ensure better care of affected children. A further, well designed study with a larger sample size is required to find more clinically relevant associations between the level of anxiety and depression and the sociodemographic and clinical factors.

\section{Study Limitations}

This study included patients with different types and stages of cancer. Sample size was not sufficient for association 
Table 5 Associations between sociodemographic and clinical factors with level of anxiety

\begin{tabular}{|c|c|c|c|c|c|c|c|c|c|}
\hline \multirow[t]{2}{*}{ Variable } & \multicolumn{2}{|c|}{ Mild anxiety } & \multicolumn{2}{|c|}{ Moderate anxiety } & \multicolumn{2}{|c|}{ Severe anxiety } & \multicolumn{2}{|c|}{ Total } & \multirow[t]{2}{*}{$p$-Value } \\
\hline & Frequency & $\%$ & Frequency & $\%$ & Frequency & $\%$ & Frequency & $\%$ & \\
\hline Gender of parents & & & & & & & & & $p=0.68$ \\
\hline Male & 12 & 21.0 & 5 & 29.4 & 5 & 18.5 & 22 & 21.8 & \\
\hline Female & 45 & 79.0 & 12 & 70.6 & 22 & 81.5 & 79 & 78.2 & \\
\hline Age of parents & & & & & & & & & $p=0.96$ \\
\hline $21-30$ & 28 & 49.1 & 8 & 47.0 & 13 & 48.2 & 49 & 48.5 & \\
\hline $31-40$ & 20 & 35.1 & 7 & 41.2 & 11 & 40.7 & 38 & 37.6 & \\
\hline$>40$ & 9 & 15.8 & 2 & 11.8 & 3 & 11.1 & 14 & 13.9 & \\
\hline Education of parents & & & & & & & & & $p=0.01$ \\
\hline No education & 5 & 8.8 & 5 & 29.4 & 6 & 22.2 & 16 & 15.8 & \\
\hline Primary/secondary & 27 & 47.4 & 6 & 35.3 & 18 & 66.7 & 51 & 50.5 & \\
\hline Inter/higher & 25 & 43.8 & 6 & 35.3 & 3 & 11.1 & 34 & 33.7 & \\
\hline Occupation & & & & & & & & & $p=0.51$ \\
\hline Employed & 36 & 63.2 & 10 & 58.8 & 20 & 74.1 & 66 & 65.4 & \\
\hline Unemployed & 21 & 36.8 & 7 & 41.2 & 7 & 25.9 & 35 & 34.6 & \\
\hline Socioeconomic class & & & & & & & & & $p=0.51$ \\
\hline Lower & 33 & 57.9 & 10 & 58.8 & 19 & 70.4 & 62 & 61.5 & \\
\hline Lower middle & 10 & 17.5 & 3 & 17.6 & 6 & 22.2 & 19 & 18.8 & \\
\hline Middle & 9 & 15.8 & 2 & 11.8 & 1 & 3.7 & 12 & 11.9 & \\
\hline Upper middle & 2 & 3.5 & 2 & 11.8 & 1 & 3.7 & 5 & 2.9 & \\
\hline Upper & 3 & 5.3 & 0 & 0 & 0 & 0 & 3 & 2.9 & \\
\hline $\begin{array}{l}\text { Distance from cancer } \\
\text { center }\end{array}$ & & & & & & & & & $p=0.99$ \\
\hline $0-20 \mathrm{~km}$ & 8 & 14.0 & 2 & 11.8 & 3 & 11.1 & 13 & 12.9 & \\
\hline $21-100 \mathrm{~km}$ & 23 & 40.4 & 7 & 41.2 & 11 & 40.7 & 41 & 40.6 & \\
\hline$>100 \mathrm{~km}$ & 26 & 45.6 & 8 & 47.0 & 13 & 48.2 & 47 & 46.5 & \\
\hline Number of children & & & & & & & & & $p=0.53$ \\
\hline 1 & 16 & 28.1 & 2 & 11.8 & 5 & 18.6 & 23 & 22.7 & \\
\hline 2 & 25 & 43.8 & 11 & 64.7 & 14 & 51.8 & 50 & 49.5 & \\
\hline$>2$ & 16 & 28.1 & 4 & 23.5 & 8 & 29.6 & 28 & 27.8 & \\
\hline Age of children & & & & & & & & & $p=0.29$ \\
\hline $0-4$ & 22 & 38.6 & 6 & 35.4 & 7 & 26.0 & 35 & 34.6 & \\
\hline $5-9$ & 17 & 29.8 & 3 & 17.6 & 9 & 33.3 & 29 & 28.7 & \\
\hline $10-14$ & 15 & 26.3 & 4 & 23.5 & 9 & 33.3 & 28 & 27.8 & \\
\hline $15-19$ & 3 & 5.3 & 4 & 23.5 & 2 & 7.4 & 9 & 8.9 & \\
\hline Time since diagnosis & & & & & & & & & $p=0.51$ \\
\hline$<1 \mathrm{mo}$ & 11 & 19.3 & 3 & 17.6 & 5 & 18.6 & 19 & 18.8 & \\
\hline $1-3 \mathrm{mo}$ & 7 & 12.3 & 4 & 23.5 & 4 & 14.8 & 15 & 14.8 & \\
\hline $3-6 \mathrm{mo}$ & 11 & 19.3 & 3 & 17.6 & 4 & 14.8 & 18 & 17.8 & \\
\hline $6-12 \mathrm{mo}$ & 8 & 14.0 & 5 & 29.5 & 8 & 29.6 & 21 & 20.8 & \\
\hline$>12 \mathrm{mo}$ & 20 & 35.1 & 2 & 11.8 & 6 & 22.2 & 28 & 27.8 & \\
\hline Cancer type & & & & & & & & & $p=0.82$ \\
\hline Hematological & 38 & 66.7 & 10 & 58.8 & 17 & 63.0 & 65 & 64.4 & \\
\hline Solid & 19 & 33.3 & 7 & 41.2 & 10 & 37.0 & 36 & 35.6 & \\
\hline
\end{tabular}


Table 5 (Continued)

\begin{tabular}{|c|l|l|l|l|l|l|l|l|l|}
\hline \multirow{2}{*}{ Variable } & \multicolumn{2}{|c|}{ Mild anxiety } & \multicolumn{2}{c|}{ Moderate anxiety } & \multicolumn{2}{c|}{ Severe anxiety } & \multicolumn{2}{c|}{ Total } & -Value \\
\cline { 2 - 10 } & Frequency & $\%$ & Frequency & $\%$ & Frequency & $\%$ & Frequency & $\%$ & \\
\hline $\begin{array}{c}\text { Time since initiation } \\
\text { of chemotherapy }\end{array}$ & & & & & & & & \\
\hline$<1$ mo & 14 & 24.6 & 4 & 23.5 & 8 & 29.6 & 26 & 25.7 \\
\hline $1-3$ mo & 6 & 10.5 & 4 & 23.5 & 4 & 14.8 & 14 & 13.9 \\
\hline $3-6$ mo & 10 & 17.5 & 2 & 11.8 & 2 & 7.5 & 14 & 13.9 \\
\hline $6-12$ mo & 9 & 15.8 & 5 & 29.4 & 7 & 25.9 & 21 & 20.8 \\
\hline$>12$ mo & 18 & 31.6 & 2 & 11.8 & 6 & 22.2 & 26 & 25.7 \\
\hline Number of visits & & & & & & & & $p=0.43$ \\
\hline $0-5$ & 17 & 29.8 & 5 & 29.4 & 13 & 48.2 & 35 & 34.6 \\
\hline $6-10$ & 20 & 35.1 & 5 & 29.4 & 5 & 18.5 & 30 & 29.7 \\
\hline$>10$ & 20 & 35.1 & 7 & 41.2 & 9 & 33.3 & 28 & 27.7 \\
\hline
\end{tabular}

studies. The factors identified are exploratory and need to be confirmed in larger subsets.

\section{Ethical Approval}

The study was conducted according to the Helsinki Declaration. Ethical approval was obtained from the institute ethical committee. Number-JIP/IEC/2018/190. This project was performed under ICMR-STS 2018.

\section{Conflict of Interest}

None declared.

\section{References}

1 Arora RS, Eden TO, Kapoor G. Epidemiology of childhood cancer in India. Indian J Cancer 2009;46(4):264-273

2 Das S, Paul DK, Anshu K, Bhakta S. Childhood cancer incidence in India between 2012 and 2014: report of a population-based cancer registry. Indian Pediatr 2017;54(12):1033-1036

3 Klassen AF, Klaassen R, Dix D, et al. Impact of caring for a child with cancer on parents' health-related quality of life. J Clin Oncol 2008;26(36):5884-5889

4 Vrijmoet-Wiersma CMJ, van Klink JM, Kolk AM, Koopman HM, Ball LM, Maarten Egeler R. Assessment of parental psychological stress in pediatric cancer: a review. J Pediatr Psychol 2008;33(7):694-706

5 World Health Organization. (2018). Depression. Available at: http://www.who.int/mental_health/management/depression/ en/. Accessed January, 20, 2018

6 Creswell PD, Wisk LE, Litzelman K, Allchin A, Witt WP. Parental depressive symptoms and childhood cancer: the importance of financial difficulties. Support Care Cancer 2014;22(2):503-511

7 Ghufran M, Andrades M, Nanji K. Frequency and severity of depression among mothers of children with cancer: results from a teaching hospital in Karachi, Pakistan. BJMP 2014;7(1):a701

8 Hutchinson KC, Willard VW, Hardy KK, Bonner MJ. Adjustment of caregivers of pediatric patients with brain tumors: a cross-sectional analysis. Psychooncology 2009;18(5):515-523

9 Wiener L, Viola A, Kearney J, et al; Lone Parent Study Group. Impact of caregiving for a child with cancer on parental health behaviors, relationship quality, and spiritual faith: do lone parents fare worse? J Pediatr Oncol Nurs 2016;33(5):378-386
10 Oppenheim D, Valteau-Couanet D, Vasselon S, Hartmann O. How do parents perceive high-dose chemotherapy and autologous stem cell transplantation for their children. Bone Marrow Transplant 2002;30(1):35-39

11 Smith MY, Redd WH, Peyser C, Vogl D. Post-traumatic stress disorder in cancer: a review. Psychooncology 1999;8(6):521-537

12 Hamilton M. A rating scale for depression. J Neurol Neurosurg Psychiatry 1960;23:56-62

13 Hamilton M. The assessment of anxiety states by rating. Br J Med Psychol 1959;32(1):50-55

14 Basher M, Karim M, Sultana N, Hossain K, Kamal M. Parent stress in childhood cancer. Bangladesh Med J 2014;41:8-13

15 Poongothai S, Pradeepa R, Ganesan A, Mohan V. Prevalence of depression in a large urban South Indian population-the Chennai Urban Rural Epidemiology Study (CURES-70) PLoS One 2009;4(9):e7185

16 Kholasehzadeh G, Shiryazdi S, Neamatzadeh H, Ahmadi N. Depression levels among mothers of children with leukemia. Iran J Ped Hematol Oncol 2014;4(3):109-113

17 Sahoo S, Khess CR. Prevalence of depression, anxiety, and stress among young male adults in India: a dimensional and categorical diagnoses-based study. J Nerv Ment Dis 2010 198(12):901-904

18 Cabral L, Duarte J, Ferreira M, dos Santos C. Anxiety, stress and depression in family caregivers of the mentally ill. Aten Primaria 2014;46(Suppl 5) :176-179

19 Sklenarova H, Krümpelmann A, Haun MW, et al. When do we need to care about the caregiver? Supportive care needs, anxiety, and depression among informal caregivers of patients with cancer and cancer survivors. Cancer 2015;121(9):1513-1519

20 de Boer-Dennert M, de Wit R, Schmitz PI, et al. Patient perceptions of the side-effects of chemotherapy: the influence of 5HT3 antagonists. Br J Cancer 1997;76(8):1055-1061

21 Erkan S, Kaplan Y. A study on the depression levels of mothers of leukemic children. Pakistan Journal of Social Sciences. 2009;6:42-47

22 Masa'Deh R, Collier J, Hall C, Alhalaiqa F. Predictors of stress of parents of a child with cancer: a Jordanian perspective. Glob J Health Sci 2013;5(6):87-88

23 Perkins SM, Shinohara ET, DeWees T, Frangoul H. Outcome for children with metastatic solid tumors over the last four decades. PLoS One 2014;9(7):e100396

24 Ma H, Sun H, Sun X. Survival improvement by decade of patients aged 0-14 years with acute lymphoblastic leukemia: a SEER analysis. Sci Rep 2014;4(1):4227 